\title{
An optimization model for transport, treatment and disposal of medical waste: a case study of Podlaskie Province
}

\author{
Maria Jolanta Walery ${ }^{1 *}$, Jacek Leszczyński ${ }^{1}$ \\ ${ }^{1}$ Bialystok University of Technology, Faculty of Civil and Environmental Engineering, Wiejska 45E, \\ Bialystok, Poland
}

\begin{abstract}
The article describes optimization studies aimed at analysing the impact of capital and current cost changes for combustion waste storage on the cost of its system management and structure. The study was conducted using the example of an analysis of the system of medical waste management in Podlaskie Province, in north-eastern Poland. The scope of operational research carried out under the optimization study was divided into two stages of optimization calculations with assumed technical and economic parameters of the system. In the first stage, the lowest cost of functioning of the analysed system was generated, whereas in the second one the influence of the input parameter of the system, i.e. capital and current costs of combustion waste storage process on the economic efficiency index (E) and the spatial structure of the system was determined. Optimization studies were conducted for the following cases: with a $25 \%$ increase in capital and current costs for the storage process, followed by $50 \%, 75 \%$ and $100 \%$ increase. As a result of the calculations, the highest cost for system operation was achieved at the level of 1655 PLN/Mg with the assumption ca. $100 \%$ increase in capital and current costs for the storage process. There was an increase in the economic efficiency index (E) by about $4 \%$ in relation to first course of optimization studies.
\end{abstract}

\section{Introduction}

Waste generated from health institutions has risks for human health and the environment. Hospitals and health centers provide a variety of healthcare services and normally generate hazardous waste as well as municipal waste. Municipal waste has a similar properties to that of municipal solid waste and therefore could be disposed of in municipal landfills after proper treatment. However, hazardous waste poses risks to public health, unless it is properly managed $[1,2,3,4]$. The quantity of waste generated from medical care and activities is a global matter of concern. The improper management of biomedical waste has a grave health impact on the community, health care professionals and the environment. It is mandatory by law that every medical organization that generates waste should have a

\footnotetext{
* Corresponding author: m.walery@pb.edu.pl
} 
system, process and resources in place for segregating biomedical waste for proper disposal $[5,6,7]$.

The traditional waste processing technologies used for the treatment of hazardous wastes are inadequate for integrating medical waste management, storage and transportation activities into comprehensive, reverse logistics operating strategies. Now, researchers have considered the use of quantitative techniques to various issues related to reverse logistics network design. Beamon and Fernandes [8] have developed an integer programming model for a four echelon reverse supply chain by assuming infinite storage capacities and same holding costs for recovered and new products. Santoso et al. [9] have proposed a stochastic programming model and solution algorithm for solving supply chain network design problems of a realistic scale. Hu, Sheu, and Huang [10] have presented a cost-minimization model for a multi-time-step, multi-type hazardouswaste reverse logistics system. Salema et al. [11] has proposed a strategic and tactical model for the design and planning of supply chains with reverse flows. Mantzaras and Voudrias [12] have focused on the analysis of optimization model to minimize the cost of a collection, transport, treatment and disposal system for infectious medical waste (The model is called IMW). The IMW model calculates the optimum locations of the treatment facilities and transfer stations, their design capacities $(\mathrm{Mg} / \mathrm{d})$, the number and capacities of all waste collection, transport and transfer vehicles and their optimum transport routh and the minimum IMW management system cost. Budak and Ustungdag [13] have conducted a study on logistical optimisation for waste collection and disposal in Turkish health institutions. A multiperiod, multitype product waste reverse logistics network was designed to build an effective collection and disposal system for waste generated from health institutions in Turkey. A mixed integer linear programming model was developed to determine the optimal number and locations of the facilities for efficient waste management in health care by minimising the total cost. In this context, a sensitivity analysis was conducted to examine the impact of the incremental changes of waste amounts on the optimal reverse logistics network. Alshraideh and Abu Qdais [14] have proposed a route scheduling model is proposed to minimize the total travel distance which in turn minimizes transportation cost and reduces emissions. The proposed model takes into account the capacity of trucks, number of visits per week, timing between visits along with the service level required by the hospitals. Qian et al. [15] have investigated a two-level hierarchical multicriteria decision model to address medical waste disposal method selection (MWDMS), where disposal methods are assessed against different criteria as intuitionistic fuzzy preference relations and criteria weights are furnished as real values. Shi et al. [16] have conducted the Mixed Integer Linear Programming model with minimizing costs for medical waste reverse logistics networks. The total costs for reverse logistics include transportation cost, fixed cost of opening the collecting centers and processing centers and operation cost at these facilities over finite planning horizons. An improved genetic algorithm method with a hybrid encoding rule is used to solve the proposed model. The efficiency and practicability of the proposed model is validated by an application to an illustrative example dealing with medical waste returned from some hospitals to a given recycling facility (packaging waste).

\section{Case study}

In this paper, the optimization model of the transport and disposal of medical waste is presented in the dynamic version, taking into account expected changes of input and output parameters of the waste management system as well as its status in given periods of time. This paper usues the optimization model of disposal and treatment of municipal waste [13], as well as a computer software MRGO+ (Model for Regional Waste Management), through 
which the model was implemented. It has been verified by the author and adapted to the needs of the proposed model to optimise the disposal and treatment of medical waste on the example of the Podlaskie Province.

The scope of operational research carried out under the optimization study was divided into two stages of optimization calculations with assumed technical and economic parameters of the system. In the first stage, the lowest cost of functioning of the analysed system was generated, whereas in the second one the influence of the input parameter of the system, i.e. capital and current costs of combustion waste storage process on the economic efficiency index (E) and the spatial structure of the system was determined.

The object of optimization studies were the influence of the input parameter of the system, i.e. capital and current costs of combustion waste storage process on the economic efficiency index (E) for the following cases: with a $25 \%$ increase in capital and current costs of combustion waste storage process, followed by $50 \%, 75 \%$ and $100 \%$ increase.

A model region in north-eastern Poland, i.e. the Podlaskie Province, was chosen for the optimization research. The input data, necessary to describe the proposed variations in the medical waste management system, has been collected and compiled in the course of analytical and field study. The optimization study which was based on real data for both technical parameters and economic quantities, allows generalizing the results and their implication for other similar regions.

18 sources of waste generation (hospitals) within the studied area of Podlaskie Province were selected for the analysis after taking into account the above mentioned technical and economic parameters of the system and environmental conditions. The study also included: four intermediate objects (medical waste incinerators), respectively: IF1 (Suwalki), IF2 (Lomza), IF3 (Bialystok) and IF4 (Hajnowka), where pyrolytic decomposition process of waste take place, and four end objects (respectively FF1, FF2, FF3, FF4) - areas for temporary storage of post-process waste from the incineration process located in the area of waste incineration facility. The model did not include restrictions on the capacity of intermediate and end objects.

The scope of operational research carried out in the framework of the optimization study was divided into successive stages in order to present options of the proposed model: Stage I - includes optimization calculations, assuming fixed technical and economic parameters. Sequence 1, made in this stage, was also a comparative course - a benchmark for other solutions and obtained results to compare.

Stage II - included a number of additional courses aimed at determining the impact of the model input parameters of the system on the indicator of expenses of economic efficiency (E) and the spatial structure of the system (system location of objects and their associated waste disposal routes).

The following input data were taken into account:

- economic parameters describing the system (waste transport unitary costs, inflation and discount rate),

- economic parameters describing the objects of the system (capital and operating costs), - the reduction of the quantity medical waste in the system of indirect objects expressed in the form of the output factor of the process (parameter wwp, \%), - the planned time horizon [t], (duration of model process).

The data relating to the costs of transport, investments and operation of the system objects, necessary for optimisation calculations, was from existing plants, located in the model region. The calculation was performed by the unit cost of the work presented in Biedugnis et al. [17] taking into account the current prices and fees. The cost of medical waste removal from the source unit to the disposal site, with the adopted technical and operational conditions is $\mathrm{K}_{\mathrm{ij}}=\mathrm{PLN}$ 9.57, and when expressed in unit cost of 1 ton of transp ort per 1 minute $(\mathrm{k})=$ PLN $1.33 / \mathrm{Mg} / \mathrm{min}$. 
The economic efficiency calculations of the method were presented in the work by Biedugnis et al. [17] whose dynamic model related to inflation and discounting of the annual capital and operating costs in each model period. Transport costs are also discounted and adjusted for inflation.

The discount rate and inflation rate of the capital cost $\left(Z_{N}{ }^{t}\right)$ and the current $\operatorname{cost}\left(Z_{E}^{t}\right)$ for the $\mathrm{t}$ model period can be expressed [17]:

$$
Z_{N}^{t}, Z_{E}^{t}=\sum_{i=1}^{m_{t}}\left(d_{t} \cdot q_{t}\right)^{i}
$$

where:

$d_{t}=1 /(1+\mathrm{r})$, discounting factor,

$q_{t}=1 /(1+\mathrm{e})$, inflation factor,

$\mathrm{r}$ - discount rate,

e- inflation rate.

Finding the best solution from the point of view of an economic efficiency indicator was set as a priority. The above mentioned criterion takes into account both the selection of waste treatment technologies, as well as search for the best relationship between the location of objects used and the associated waste transport route network, depending on the amount of waste transported in each model periods.

\section{Results and discussion}

Calculations were carried out in the following courses:

Stage I - course 1: duration of model period, respectively $\mathrm{t} 1=5$ and $\mathrm{t} 2=15$ years, the unitary cost of transportation of medical waste in the first and second model period, respectively, 1.33 and $0.44 \mathrm{PLN} / \mathrm{Mg} / \mathrm{min}$, the level of reduction of the quantity medical waste in the intermediate facilities expressed as a coefficient of the process output, wwp $=10 \%$.

Stage II - in courses 2-5 - the impact of changes in capital and current costs of waste storage process on the cost of the system and its structure was investigated: respectively for course 2 - with a 25\% increase in capital and current costs; For course 3 - with a 50\% increase in capital and current costs; For course 4 - with a $75 \%$ increase in capital and current costs and for course 5 - with a $100 \%$ increase in capital and current costs of storage process.

As a result of optimization calculations for course 1 (Stage I) of the pre-established model system of the 26 facilities (18 - the source of the medical waste, 4 - incineration, 4 storage of hazardous waste, 55 - possible routes for waste transport), there was a number of facilities selected in model periods I and II: $3 / 3$ incinerators, $3 / 3$ of the landfills and 21/21 waste transport routes, consequently minimizing the cost of the system. Process levels in intermediate and final facilities in each model period for Stage I are presented in Table 1. 
Table 1. The level of processing activities of intermediate and final objects for the $1^{\text {st }}$ course $[\mathrm{Mg} /$ year $]$.

\begin{tabular}{|c|c|c|c|}
\hline System facilities & Process & $\begin{array}{l}\text { Processing activity } \\
\text { level }[\mathrm{Mg} / \text { year }]\end{array}$ & $\begin{array}{l}\text { Duration of model studies } \\
\mathrm{I}=5 \text { years, } \mathrm{II}=15 \text { years }\end{array}$ \\
\hline IF1 & incineration & 140.400 & I \\
\hline IF1 & incineration & 148.800 & II \\
\hline IF2 & incineration & 210.400 & I \\
\hline IF2 & incineration & 222.400 & II \\
\hline IF3 & incineration & 434.400 & I \\
\hline IF3 & incineration & 450.900 & II \\
\hline FF1 & storage & 14.040 & I \\
\hline FF1 & storage & 14.880 & II \\
\hline $\mathrm{FF} 2$ & storage & 21.040 & I \\
\hline $\mathrm{FF} 2$ & storage & 22.240 & II \\
\hline FF3 & storage & 43.440 & I \\
\hline FF3 & storage & 45.090 & II \\
\hline
\end{tabular}

In subsequent courses 2, 3, 4 and 5 the impact of changes in the capital and current costs of waste storage process on the cost of the system and its structure was investigated: respectively for course 2 - with a $25 \%$ increase in capital and current costs; For course 3 with a $50 \%$ increase in capital and current costs; For course 4 - with a $75 \%$ increase in capital and current costs and for course 5 - with a 100\% increase in the capital and current costs of waste storage process.

The highest economic efficiency index $\mathrm{E}=1655 \mathrm{PLN} / \mathrm{Mg}$ was achieved with a $100 \%$ increase in capital and current costs. This index (E) increased by approx. $4 \%$ in relation to course 1. Figure 1 shows the values of the economic efficiency index (E) for courses 2-5, depending on the capital and current costs of the storage process. 


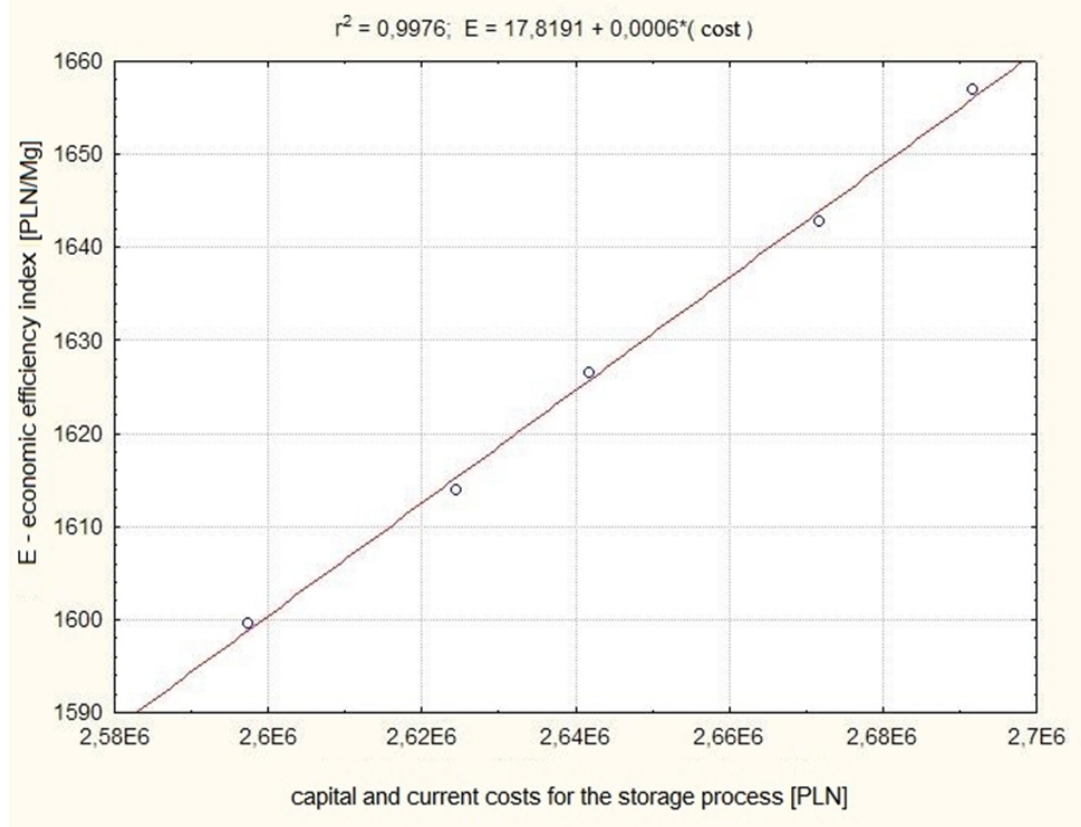

Fig. 1. Correlation of the economic efficiency index (E) and the capital and current costs for the storage process.

\section{Conclussions}

As a result of a well-developed and properly implemented waste management program, the medical facility can gain significant savings in the area of current the medical waste management. Conducting waste management in a rational manner and consistent with environmental protection regulations may significantly reduce the amount of waste, which leads to a reduction in the costs of its neutralisation.

The costs of managing hazardous waste (often municipal waste is stored of managed together with hazardous waste) are on average five times higher than the cost of disposal of municipal waste, and the recovery and recycling of recyclable materials (plastics, paper, glass packaging) from some waste from medical facilities, allows not only to obtain profits from their sale, but also avoiding costs incurred for landfilling.

In the case of the capital and current costs of the combustion waste storage process, it should be stated that in comparison with the costs of the combustion process [18], they cause a smaller change in E economic efficiency index, because landfilling of combustion waste belong to entities with significantly lower total costs.

Optimization studies yielded the highest economic efficiency index $(\mathrm{E})=1655 \mathrm{PLN} / \mathrm{Mg}$ with the assumed $100 \%$ increase in capital and current costs for the storage process. The economic efficiency index (E) increased by ca. $4 \%$.

The increase in capital and current costs for the storage process is accompanied by an increase in the economic efficiency ratio $(\mathrm{E})$ :

$\mathrm{E}($ cost for the storage process $)=17,8191+0.0006 \cdot($ cost $)[\mathrm{PLN} / \mathrm{Mg}]$. 
The research was conducted as part of the $\mathrm{S} / \mathrm{WBiIS} / 2 / 14$ project and financed by the Ministry of Science and Higher Education science fund.

\section{References}

1. B.C. D’Souza, A.M. Seetharam, V. Chandrasekaran, R. Kamath, I. J. Health. Manage., 11, 1 (2018)

2. D.V.G. Delmonico, H.H. Santos, M.A.P. Pinheiro, R. Castro, R.M. Souza, Waste Manage., 36, 1 (2018)

3. I.A. Al-Khatib, D. Eleyan, J. Garfield, Environ. M. Ass., 188, 9 (2016)

4. P. Sahni, G. Arora, A.K. Dubey, Comm. Comput. I. Sci., 799 (2018)

5. G.R.M.D. Freitas, M.Y. Tramontina, G. Balbinotto, D.A. Hughes, I. Heineck, V. H. Reg. Iss., 14 (2017)

6. B. Sadowska-Buraczewska, P. Rutkowski. Ann. S. Environ. P., 5 (2013)

7. M.A. Shirazi, R. Samieifard, A.M. Abduli, B. Omidvar, J Environ. Health Sci. Eng. 14, 8 (2016)

8. B.A. Beamon, C. Fernandes, Prod. Plann.Cont., (2004)

9. T. Santoso, S. Ahmed, M. Goetschalckx, A. Shapiro, Europ. J. Op. (2005)

10. T.L. Hu, J.B. Sheu, K.H. Huang, Transp. Res. P. E (2002)

11. M.I. Salema, A.P. Barbosa, A.Q. Novais, Ind.. Eng. J. (2006)

12. G. Mantzaras, E.A. Voudrias, Waste Manage. 69 (2017)

13. A. Budak, A. Ustungdag, I. J. L. Res. App., 20, 4 (2017)

14. H.Alshraideh, H. Abu Qdais, J. M. Cycle Waste Manage.,19, 2 (2017)

15. W. Qian, Z.J. Wang, K.W. Li, I. J. Environ. Res. Pub. Health, 13, 9 (2016)

16. L. Shi, H. Fan, P. Gao, H. Zhang, L. N. C. Sc., 5821 (2009)

17. S. Biedugnis, P. Podwójci, M. Smolarkiewicz, Optimization of municipal waste management in micro and macro-region scale (2003)

18. M.J. Walery, Earth Environ. Sci, 95 (2017) 